Research Council of Canada (\#MA-14675) and the Physicians Services Incorporated Foundation of Ontario (\#98-08). Competing interests: None declared.

1 Daniels N, Sabin JE. Limits to health care: fair procedures, democratic deliberation and the legitimacy problem for insurers. Philosophy and Public Affairs 1997;26:303-50.

2 Singer PA. Resource allocation: beyond evidence-based medicine and cost-effectiveness analysis. ACP Journal Club 1997;127:A16-8.

3 Martin DK, Singer PA. Priority setting and health technology assessment: beyond evidence based medicine and cost effectiveness analysis. In: Ham C, Coulter A, eds. Priorities in health care. Buckingham: Open University Press (in press).

4 Newhouse JP. Medical care costs: how much welfare loss? Journal of Economic Perspectives 1992;6(3):3-21.

5 Yin RK. Case Study research: design and methods. Thousand Oaks, CA: Sage Publications, 1994:13.

6 Strauss AL, Corbin JM. Basics of qualitative research: grounded theory procedures and techniques. Newbury Park, CA: Sage Publications, 1990.

7 Cardiac Care Network of Ontario Expert Review Panel on Intracoronary Stents and Abciximab. Final report and recommendations. Ontario: CCNO, 1998.
8 Foy R, So J, Rous E, Scarfe JH. Perspectives of commissioners and cancer specialists in prioritising new cancer drugs: impact of the evidence threshold. BMI 1999;318:456-9.

9 Hope T, Hicks N, Reynolds DJM, Crisp R, Griffiths S. Rationing and the health authority. BMJ 1998;317:1067-9.

10 Green J. Commentary on: Gardner K, Chapple A. Barriers to referral in patients with angina: qualitative study. BMJ 1999;319:418-21.

11 Klein R, Day P, Redmayne S. Managing scarcity: priority setting and rationing in the National Health Service. Buckingham: Open University Press, 1996

12 Klein R. Puzzling out priorities: why we must acknowledge that rationing is a political process. BMJ 1998;317:959.

13 Ham C. Priority setting in health care: learning from international experience. Health Policy 1997:42:49-66.

14 Ham C. Tragic choices in health care: lessons from the child B case. $B M J$ 1999:319:1258-61.

15 Holm S. Goodbye to the simple solutions: the second phase of priority setting in health care. BMJ 1998;317:1000-2.

16 Daniels N, Sabin J. The ethics of accountability in managed care reform. Health Affairs 1998;17:50-64

17 Daniels N, Sabin JE. Last chance therapies and managed care: pluralism, fair procedures, and legitimacy. Hastings Center Report 1998;28(2):27-41. (Accepted 3 October 2000)

\title{
Serosurveillance of prevalence of undiagnosed HIV-1 infection in homosexual men with acute sexually transmitted infection
}

\author{
Michael A Catchpole, Christine A McGarrigle, Pauline A Rogers, Laura F Jordan, Danielle Mercey, \\ O Noel Gill
}

The prevalence of HIV-1 infection among homosexual and bisexual men attending genitourinary medicine clinics, measured through anonymised testing of samples taken to test for syphilis, has declined in recent years. ${ }^{1}$ This decline may be spurious, however, because the proportion of such men who have serum samples taken to test for syphilis has declined and because specialist HIV services have drawn patients infected with HIV away from the genitourinary medicine clinics that participate in seroepidemiological surveillance. ${ }^{2}$ We therefore studied the prevalence of HIV-1 in homosexual and bisexual men without a diagnosis of HIV-1 infection who presented with a new episode of an acute sexually transmitted infection: this group is likely to attend genitourinary medicine clinics and undergo testing for syphilis.

\section{Methods, and results}

A continuing survey in England and Wales in 15 genitourinary medicine clinics uses specimens left over after testing for syphilis. ${ }^{3}$ The data collected (time and place of attendance, the patient's characteristics and risks for HIV-1 infection, and the presence of HIV-1 infection or an acute sexually transmitted infection) and the remains of the specimen are unlinked and anonymised before testing for HIV-1. Infections probably acquired through unprotected sex, such as gonorrhoea, chlamydia, and first episodes of viral sexually transmitted infections, were categorised as acute sexually transmitted infections. Trends in the prevalence of HIV-1 infection among homosexual and bisexual men were adjusted for clinic, age group, injecting drug use, and presence of acute sexually transmitted infection and analysed by multivariable logistic regression in GLIM-4 (Numerical Algorithms Group, Oxford). The unit of analysis was each new attendance per quarter.
Repeat attendances are not identified but are unlikely to exceed 3\% per six month period (Communicable Disease Surveillance Centre, unpublished data).

Altogether, 32006 attendances were analysed. In London, the observed prevalence of HIV-1 declined among all patients presenting with an acute sexually transmitted infection (figure), from 16.5\% (110/667) in
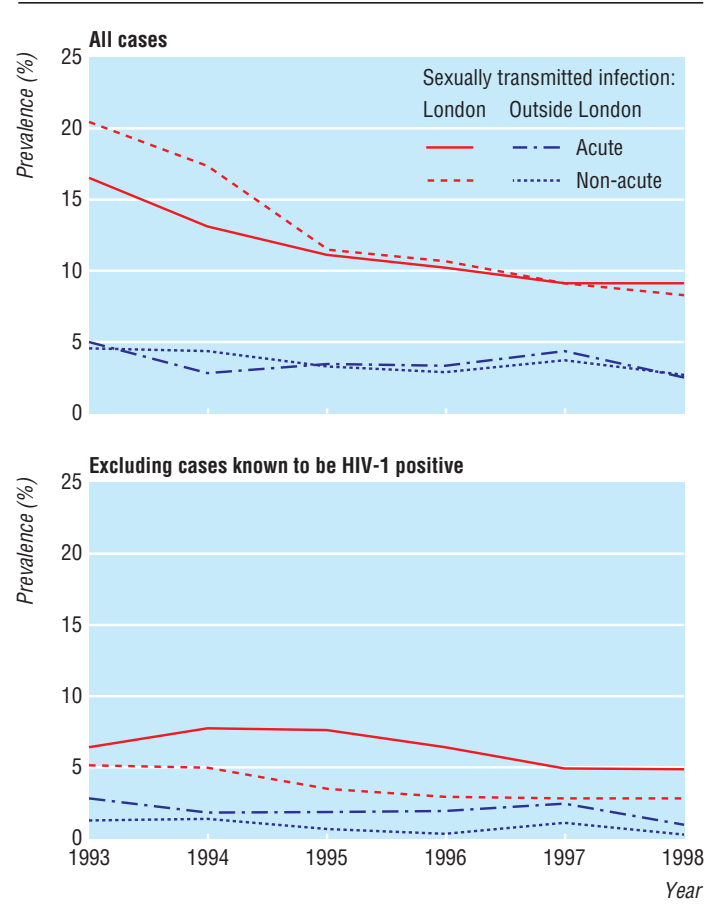

Unadjusted prevalence of HIV-1 for homosexual and bisexual men by year of attendance
HIV-STI Section, Public Health Laboratory Service Communicable Disease

Surveillance Centre, London NW9 5EQ

Michael A

Catchpole consultant epidemiologist

Christine A McGarrigle clinical scientist Laura F Jordan scientist

O Noel Gill

consultant epidemiologist

Public Health Laboratory Service Statistics Unit, Communicable

Disease

Surveillance Centre Pauline A Rogers statistician

Department of Sexually

Transmitted

Diseases, Royal Free and University

College Medical

School, London

WC1E 6AU

Danielle Mercey

consultant genitourinary physician

Correspondence to: M A Catchpole mcatchpole@phls. nhs.uk

BMJ 2000;321:1319-20 
1993 to $9.0 \%(123 / 1373)$ in 1998 , an adjusted average decrease of $9 \%$ a year $(95 \%$ confidence interval decrease $1 \%$ to $16 \%)$. When specimens from men known to be HIV-1 positive were excluded there was no adjusted trend in prevalence, which was 4.9\% $(64 / 1314)$ in 1998. The adjusted decline in prevalence of HIV-1 among homosexual and bisexual men presenting with non-acute sexually transmitted infections was significant: $17 \%$ a year (12\% to $21 \%)$ overall and $11 \%$ a year $(7 \%$ to $16 \%)$ when men known to be HIV-1 positive were excluded.

Outside London, the observed prevalence of HIV-1 among homosexual and bisexual men was lower (figure), and the adjusted decrease in prevalence overall was significant only in men presenting with non-acute sexually transmitted infections (average decrease of $11 \%$ a year ( $4 \%$ to $18 \%)$ ).

The proportion of all attenders with an acute sexually transmitted infection increased over time in London, but not outside London. This trend was less apparent when attenders known to be HIV-1 positive were excluded.

\section{Comment}

In 1993-8 the prevalence of undiagnosed HIV-1 infection in homosexual and bisexual men presenting with acute sexually transmitted infection did not fall, which indicates a high level of continuing transmission. The smaller increase in this group of men in London is consistent with a progressive drawing away of men infected with HIV from participating clinics or a reduction in syphilis testing of HIV infected attenders without an acute infection.
The difference in trends between men with and without acute sexually transmitted infections may be partly because of repeat sampling of a core group of HIV-1 infected men with repeated new infections. If so, it will represent a marker of significant risk for HIV-1 transmission in the population. These men probably have more partners and engage in riskier sex than those without an acute sexually transmitted infection. ${ }^{4}$ The facilitatory effect of many acute infections on HIV-1 transmission ${ }^{5}$ may also have contributed to the higher prevalence. Health promotion directed at this group of men should be intensified.

Contributors: MAC, ONG, and DM conceived and designed the study. PAR was responsible for the statistical analysis in collaboration with CAMcG and LFJ. CAMcG and LFJ coordinated the study. CAMcG interpreted the data together with MAC and PAR. MAC, CAMcG, and ONG prepared the paper in consultation with the other authors. MAC is the guarantor for the paper. Funding: Department of Health.

Competing interests: None declared.

1 Unlinked Anonymous HIV Surveys Steering Group. Prevalence of HIV in the United Kingdom, data to end 1998. London: Department of Health, 1999.

2 Nardone A, Rogers P, Joyce C, Nicoll A, Mercey D. The interpretation of trends in HIV seroprevalence amongst homo/bisexual men attending a GUM clinic in central London. MRC AIDS Research Workshop Abstract Book 1995;4-5:29.

3 Simms I, Rogers P, Catchpole M, McGarrigle CA, Nicoll A on behalf of the collaborative group. Trends in undiagnosed HIV-1 infection among attenders at genitourinary medicine clinics: 1990-6. Sex Transm Inf 1999;75:332-6.

4 Catchpole M, Connor N, Brady A, Kinghorn G, Mercey D, Band B, et al. Behavioural and demographic characteristics of attenders at two genitourinary medicine clinics in England. Genitourin Med 1997:73:457-61.

5 Grosskurth H, Mosha F, Todd J, Mwijarubi E, Klokke A, Senkoro K, et al. Impact of improved treatment of sexually transmitted diseases on HIV infection in rural Tanzania: randomised controlled trial. Lancet 1995;346:530-6.

(Accepted 5 July 2000)

\title{
Body mass and probability of pregnancy during assisted reproduction treatment: retrospective study
}

\author{
J X Wang, M Davies, R J Norman
}

Department of

Obstetrics and

Gynaecology,

University of

Adelaide, Queen

Elizabeth Hospital,

Woodville, SA 5011 ,

Australia

J X Wang

senior research officer

M Davies

senior research fellow

R J Norman

professor of

reproductive medicine

Correspondence to:

J X Wang

jwang@medicine.

adelaide.edu.au

BMJ 2000;321:1320-1
Being underweight or overweight has an adverse effect on reproduction. ${ }^{12}$ Overweight women have a higher incidence of menstrual dysfunction and anovulation, possibly because of altered secretion of pulsatile gonadotropin releasing hormone, sex hormone binding globulin, ovarian and adrenal androgen, and luteinising hormone and also because of altered insulin resistance. The prevalence of obesity in infertile women is high, but there is no conclusive evidence that extremes of weight are associated with a low rate of pregnancy in women receiving assisted reproduction treatment. This study examined whether body mass index (weight $(\mathrm{kg}) /\left(\right.$ height $\left.\left.(\mathrm{m})^{2}\right)\right)$ is associated with reduced fecundity (the probability of achieving at least one pregnancy during treatment) in women receiving assisted reproduction treatment.

\section{Participants, methods, and results}

The participants were 3586 women who received assisted reproduction treatment between 1987 and 1998 in a tertiary medical unit in Adelaide, South Australia.
Treatments included in vitro fertilisation $(n=1972)$, intracytoplasmic sperm injection $(n=1040)$, and gamete intrafallopian transfer $(n=574)$. Patients underwent 8822 embryo transfer cycles. The overall implantation rate was $12.0 \%$, and the clinical pregnancy rate was $24.1 \%$ in the study population. Causes of infertility included tubal blockage (34\%), semen defects (35\%), unexplained infertility (16\%), and endometriosis $(9 \%)$. Age of participants, treatment modalities, location of the treatment, number of embryos transferred, number of cycles of embryo transfer, and number of oocytes recovered were analysed to eliminate possible confounding effects. Polycystic ovarian syndrome was diagnosed, using normal criteria, in 25\% (881/3586) of the women. ${ }^{3}$

Participants were stratified into five groups according to body mass index: "underweight" $(<20)$, "moderate" (20.0-24.9), "overweight" (25.0-29.9), "obese" (30.0-34.9), and "very obese" ( $\geqslant 35)$. Fecundity was defined as the probability of achieving at least one pregnancy throughout the treatment. Pregnancy was determined by ultrasonography of the embryonic sac (or sacs) in the womb at 4-6 weeks after embryo transfer. 